Review

\title{
Red Wine Polyphenols for Cancer Prevention
}

\author{
Shan He, Cuirong Sun * and Yuanjiang Pan * \\ Department of Chemistry, Zhejiang University, Hangzhou 310027, P. R. China
}

* Authors to whom correspondence should be addressed. E-mail: cheyjpan@zju.edu.cn; Tel: +86-57187953000; Fax: +86-571-87951629

Received: 24 April 2008; in revised form: 5 May 2008 / Accepted: 5 May 2008 / Published: 20 May 2008

\begin{abstract}
Conventional cancer therapies, the second leading cause of death worldwide, result in serious side effects and, at best, merely extend the patient's lifespan by a few years. Searching for effective prevention is of high priority in both basic and clinical sciences. In recent decades natural products have been considered to be an important source of cancer chemopreventive agents. Red wine polyphenols, which consisted of various powerful antioxidants such as flavonoids and stilbenes, have been implicated in cancer prevention and that promote human health without recognizable side effects. Since resveratrol, a major component of red wine polyphenols, has been studied and reviewed extensively for its chemopreventive activity to interfere with the multi-stage carcinogenesis, this review focuses on recent progress in studies on cancer chemopreventive activities of red wine polyphenol extracts and fractions as well as other red wine polyphenols, like procyanidin B5 analogues and myricetin.
\end{abstract}

Keywords: Red wine polyphenols, cancer prevention, carcinogenesis, aromatase inhibitor, myricetin

\section{Introduction}

Cancer is one of the main reasons of death in both men and women, claiming over 6 million people each year worldwide. Chemoprevention, a relatively new and promising strategy to prevent cancer, is defined as the use of either natural or synthetic substances or their combinations to block, reverse or retard the process of carcinogenesis [1]. In spite of substantial progress in the development of 
anticancer therapies, the incidence of cancer is still increasing worldwide. Carcinogenesis is generally recognized as a multi-step process in which distinct molecular and cellular alterations occur. From the studies of experimentally induced carcinogenesis in rodents, its development is considered to consist of several separate, but closely linked, stages - initiation, promotion and progression. And it takes many years to turn into complete malignancy. Therefore, there are ample opportunities to intervene in the development of cancer before the onset of malignancy.

A diet rich in vegetable and fruit reduces the risk of cancer [2]. Polyphenols in these foods and beverages are thought to be among the constituents responsible for the reduced cancer risk because they are protective in cell cultures and in animals pretreated with carcinogenic chemicals [3-9] or cancer cells [10]. Grapes and red wine are an abundant source of polyphenols and represent an important dietary component for some populations. In recent years, a large body of literature has been devoted to studies describing the potential cancer chemopreventive activities of red wine polyphenols $[11,12]$, which have been shown to block carcinogenesis and to inhibit the growth of tumors in whole animals or in cell culture. In many instances, these effects can be attributed to plausible biochemical mechanisms including enhanced apoptosis, growth arrest at one or more phases in cell cycle, inhibition of DNA synthesis, and modulation of signal transduction pathways by altered expression of key enzymes such as cyclooxygenases and protein kinases [13, 14]. Moreover, consumption of polyphenols from wine could account for the lower risk of rectal cancer among wine drinkers, compared to consumers of beer and spirits [15].

Since a pioneering study by Pezzuto and colleagues [16], resveratrol, a major component of red wine polyphenols, has been studied and reviewed extensively for the chemopreventive activity to interfere with the multistage carcinogenesis $[17,18]$. However, resveratrol was not believed to be the only phytochemical that contribute to the chemopreventive activity of red wine. In this review we focus on recent progress in studies on cancer chemopreventive activities of red wine polyphenol extracts and fractions as well as other red wine polyphenols.

\section{Cancer chemopreventive activities of red wine polyphenol extracts and fractions}

In recent years, experimental studies have shown that polyphenols from red wine, like resveratrol [16], quercetin [19], (+)-catechin [20] and gallic acid [21], were potential cancer chemopreventive agents. However, red wine contains a wide range of different polyphenols [22] and protective effects have not been assigned to a specific fraction or compound, so it is not yet clear which compounds present in red wine are endowed with protective activity. Therefore, to investigate the cancer chemopreventive effects of red wine polyphenols as total extract or fractions are of importance.

In 1996, Clifford and coworkers investigated the cancer chemopreventive activities of dehydrateddealcoholized red wine solids, which were consumed as part of a precisely defined complete diet. Sibling transgenic mice were weaned onto an amino acid-based diet alone or supplemented with red wine solids. The supplemented diet was fed continuously for three generations to ensure that it supported normal growth and reproduction. Red wine solid supplement was reported to delay tumor onset, that intact catechin was absorbed, and that the supplemented diet supported normal growth and reproduction for three generations. Therefore, red wine solids may be a useful dietary supplement for animal studies and human clinical trials [23]. 
In 2000, Caderni and coworkers made a comparison among extracts from black and green tea and red wine of their effects on azoxymethane (AOM) induced intestinal carcinogenesis. Male F344 rats were treated with $\mathrm{AOM}$ and then allocated into groups receiving black tea, green tea or red wine extracts mixed in their diet. In the rats treated with black tea or wine extracts, there were significantly fewer colorectal tumours than in controls. Significantly fewer rats in the black tea and wine extract groups had adenomas than in controls. The tumours from the black tea group and, to a lesser extent, those from the wine group, had a significantly greater apoptotic index than tumours in controls. In contrast, the apoptotic index of the normal mucosa did not vary among groups. These findings indicated that black tea and wine extracts, but not green tea extracts, could protect against AOMinduced colon carcinogenesis by a mechanism probably involving increased apoptosis in tumours [24]. In continuation, the research group recently investigated the effect of high molecular weight polyphenols (HMWP), low molecular weight polyphenols (LMWP) and total polyphenolic extracts from red wine (WE) on colon carcinogenesis. Their results demonstrated that total WE, but neither the HMWP nor the LMWP, have inhibitory effect on the process of colon carcinogenesis induced by dimethylhydrazine (DMH). These conclusions were in accordance with previous observations, showing that HMWP do not inhibit aberrant crypt foci (ACF), putative preneoplastic lesions [25]. They suggested that a protective effect of wine polyphenols is better observed administering a complex mixture [26].

In 2002, Briviba and coworkers showed that red wine polyphenols inhibited the proliferation of transformed colon epithelial cells HT 29 clone 19A induced by epidermal growth factor (EGF). Inhibition of proliferation was also associated with modulation of activation of mitogen-activated protein kinases (MAPK). Stress activated c-Jun N-terminal kinases 1/2 (JNK) and p38 MAPK were significantly activated by red wine polyphenols. Maximum phosphorylation of MAPK was observed after treatment with red wine polyphenols. Furthermore, activation of extracellular signal regulated kinase (ERK) 1/2 by EGF was significantly inhibited by red wine polyphenols. This signaling pattern, activation of JNK $1 / 2$ and p38 MAPK and inhibition of ERK 1/2, is typical for anti-proliferative compounds, indicating that red wine polyphenols may inhibit the proliferation of colon carcinoma cells by modulating MAPK intracellular signal transduction pathways [27].

In 2005, Dolara and coworkers reported that red wine polyphenols administered with the diet to F344 rats for 16 weeks inhibited colon carcinogenesis induced by AOM or DMH. Furthermore the molecular effects of wine polyphenols were investigated by the microarray technology to study gene expression profiles. Global expression analysis of 5707 genes revealed an extensive down-regulation of genes involved in a wide range of physiological functions, such as metabolism, transport, signal transduction and intercellular signaling (Figure 1). It was observed that two major regulatory pathways were down-regulated in the colon mucosa of polyphenols-treated rats: inflammatory response and steroid metabolism. Furthermore, a down-regulation of many genes regulating cell surface antigens, metabolic enzymes and cellular response to oxidative stress was also observed. In conclusion, reduction of oxidative damage, modulation of colonic flora and variation in gene expression may all concur in the modulation of intestinal function and carcinogenesis by red wine polyphenols [28]. 
Figure 1. Diagram of the down-regulated genes after polyphenol-treatment and their function. The $\%$ indicated the $\%$ frequency of genes in a functional class relative to the total amount of genes varied by the treatment [28].

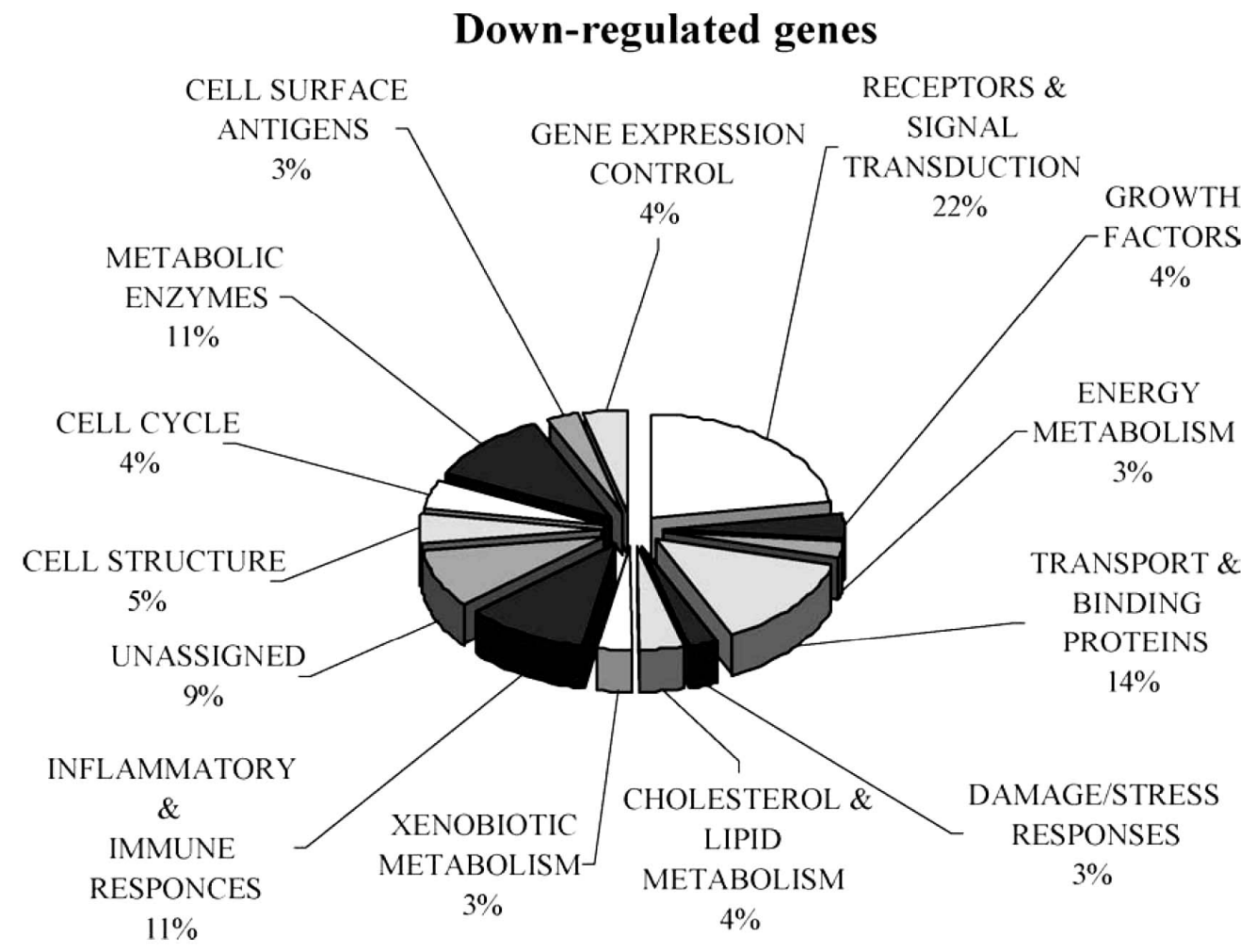

In a more recent study [29], the mechanism of selective cytotoxicity induced by red wine polyphenols against MCF-7 breast cancer cells was investigated in relation to their interference with calcium homeostasis. MCF-7 cells showed an increase in cytosolic calcium levels within 10 min of treatment with the polyphenols. MCF-7 cells treated with the red wine polyphenol fraction (RWPF) showed swelling of endoplasmic reticulum, dissolution of the nucleus, and loss of plasma membrane integrity as well as reduced mitochondrial membrane potential. These cells were arrested at the G2/M interphase. By contrast, MCF-10A cells did not show such changes after RWPF treatment. The results suggest that polyphenol-induced calcium release may disrupt mitochondrial function and cause membrane damage, resulting in selective cytotoxicity toward MCF-7 cells. This property could further be developed toward breast cancer prevention strategies either independently or in conjunction with conventional prevention therapies where a positive drug-nutrient interaction could be demonstrated.

\section{Red wine polyphenols as aromatase inhibitors: potential preventive strategy of breast cancer}

Estrogens play an important role in breast cancer development. Approximately $60 \%$ of premenopausal and $75 \%$ of postmenopausal patients have estrogen-dependent carcinomas. Aromatase, a cytochrome $\mathrm{P} 450$, is the enzyme that synthesizes estrogens by converting $\mathrm{C} 19$ androgens into aromatic $\mathrm{C} 18$ estrogenic steroids. In breast tumors, expression of aromatase is upregulated compared to that of surrounding noncancerous tissue [30-33]. Furthermore, estrogen produced in situ has a stronger influence than endogenous circulatory estrogen in breast tumor growth $[34,35]$. Therefore, 
suppression of in situ estrogen formation in the breast of postmenopausal women by aromatase inhibitors is considered to be a useful approach for prevention and treatment of breast cancer.

Enlightened by the finding that grape juice contained chemicals that act as potent inhibitors of aromatase [36], Eng and coworkers investigated aromatase inhibitory activities of grape wines [37]. Red wine was shown to be much more effective than white wine in suppression of aromatase activity (Table 1). C18 Sep-Pak cartridge (Waters Co.) separation of red wine extracts under an increasing acetonitrile $(\mathrm{ACN})$ gradient found that the most active components were in the $20 \% \mathrm{ACN}$ fraction, in that they inhibited the wild-type human placenta aromatase, wild-type porcine placenta and blastocyst aromatase in a dose-dependent fashion. The $20 \%$ ACN active fraction was heat stable and inhibited aromatase in a non-competitive manner. The aromatase-inhibitory action of red wine extracts was also examined with a transgenic mouse model in which aromatase is over-expressed in the mammary tissues. It was found that the intake of the $20 \% \mathrm{ACN}$ fraction by gavage completely abrogated aromatase-induced hyperplasia and other changes in the mammary tissue (Figure 2). These results suggested that red wine or red wine extract might be a chemopreventive diet supplement for postmenopausal women who have a high risk of breast cancer [38].

Table 1. Inhibitory effect on human placental aromatase activity by complete red or white wines [38].

\begin{tabular}{ll}
\hline Wine & $\begin{array}{l}\text { Percent remaining } \\
\text { aromatizer activity }\end{array}$ \\
\hline Red wine & \\
Cabernet Sauvignon, Tanglewood, 1996 & 0.29 \\
Cabernet Sauvignon, Glen Ellen Prp Reserve ,1997 & 7.7 \\
Cabernet Sauvignon, San Andrés, 1998 & 0.36 \\
Merlot, JW Morris, 1997 & 0.42 \\
Merlot, Forest Ville, 1997 & 0.46 \\
Merlot, Hacienda, 1997 & 3.29 \\
Merlot, Hacienda, 1998 & 0.9 \\
Zinfande, Black Mountain, 1996 & 0.39 \\
Zinfandel, Sequoia Ridge ,1996 & 0.39 \\
Pinot Noir, Cambiaso, 1996 & 0.34 \\
Pinot Noir, Hacienda, 1996 & 2.16 \\
White wine & \\
Chardonnay Woodbridge, 1998 & 99.1 \\
Chardonnay, Santa Rita Reserve, 1999 & 80 \\
Fumé Blanc, Domaine Napa, 1996 & 112.5 \\
Sauvignon Blanc, Turning Leaf, 1998 & 106.5 \\
\hline
\end{tabular}


Figure 2. Red wine extract completely abrogated aromatase-induced hyperplasia and other changes in the mammary gland (B), ovary $(\mathrm{E})$ and uterus $(\mathrm{H})$, as compared to the control group (A, D and G), which showed comparable effects with Letrzole (C, F and I), a well known aromatase inhibitor. [37]

Aromatase Control
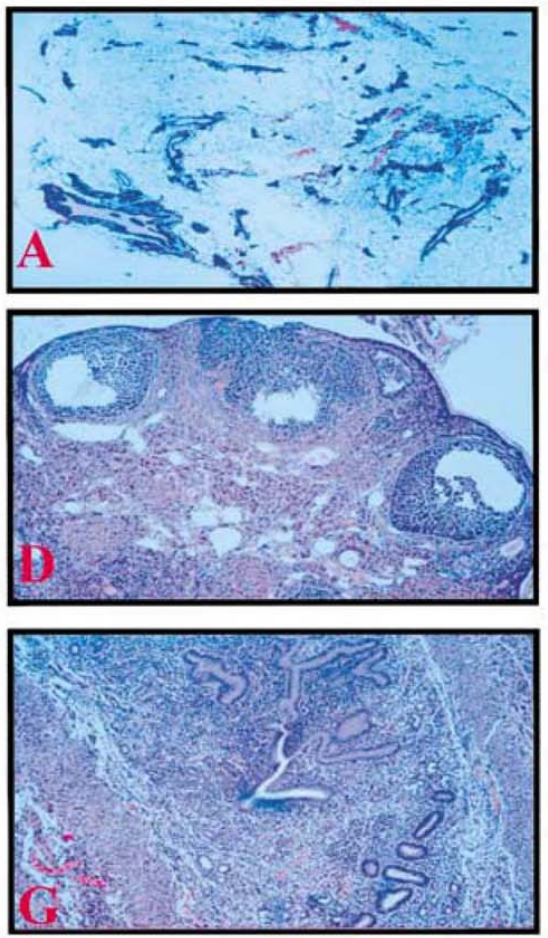

Red wine extract
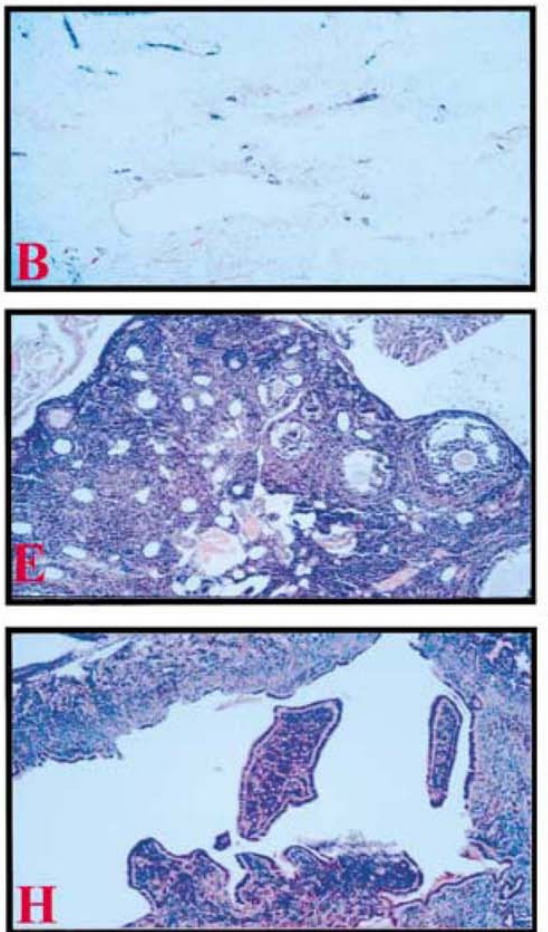

Letrozole
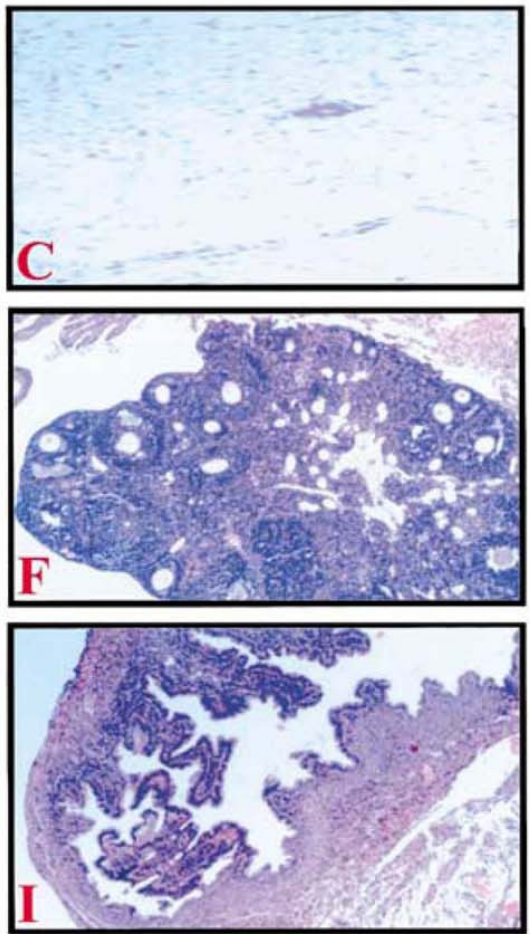

In 2003, Eng and coworkers isolated the active compounds from the red wine fraction, which were identified as procyanidin B dimers (Figure 3) that were shown to be aromatase inhibitors [39]. Inhibition kinetic analysis on the most potent procyanidin B dimer has revealed that it competed with the binding of the androgen substrate with a $K_{i}$ value of $6 \mu \mathrm{M}$. Because mutations at Asp-309, Ser-378, and His-480 of aromatase significantly affected the binding of the procyanidin B dimer, these active site residues were thought to be important residues that interact with this phytochemical. The in vivo efficacy of procyanidin B dimers was evaluated in an aromatase-transfected MCF-7 breast cancer xenograft model. The procyanidin B dimers were able to reduce androgen-dependent tumor growth, indicating that these chemicals suppress in situ estrogen formation. These in vitro and in vivo studies demonstrated that procyanidin B dimers in red wine and grape seeds could be used as chemopreventive agents against breast cancer by suppressing in situ estrogen biosynthesis [39]. 
Figure 3. The chemical structure of procyanidin B5. Procyanidins B5-B8 are dimers with the 4-6 linkage and stereoisomers at position C-3.

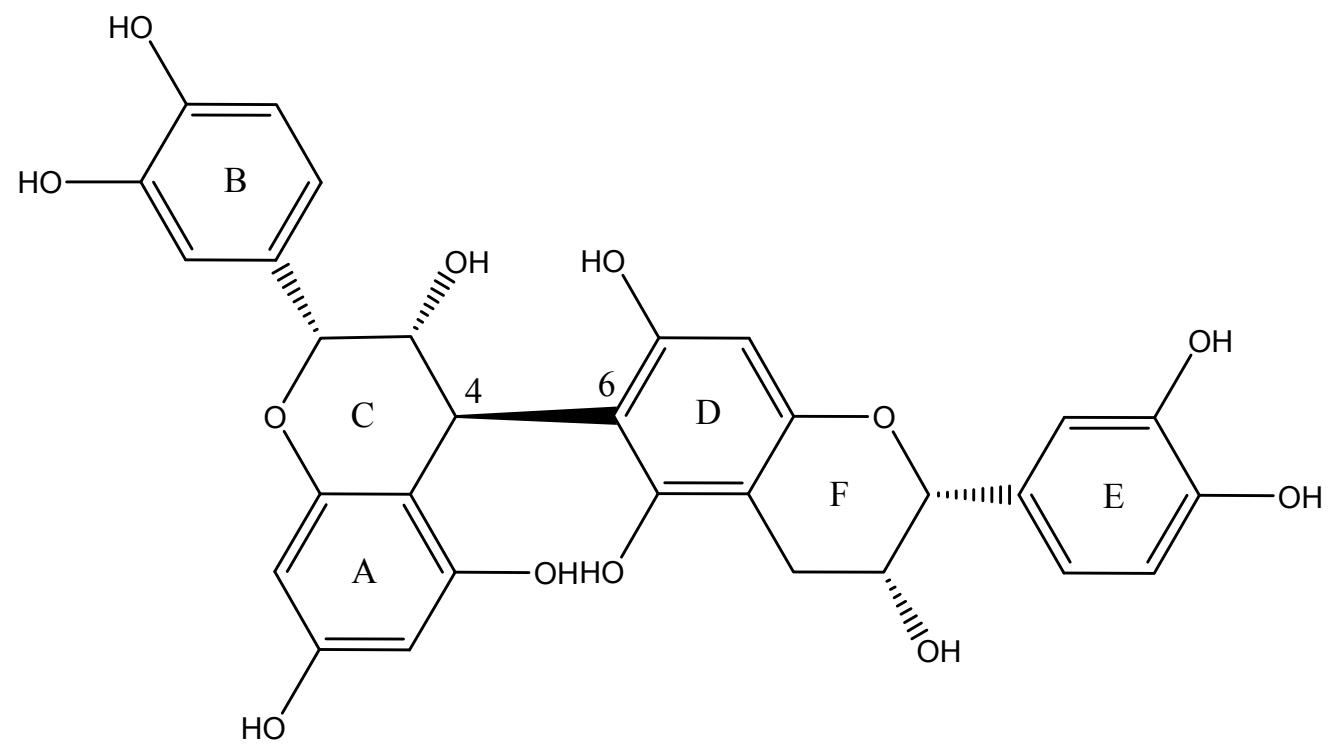

\section{Cancer chemopreventive activities of myricetin}

Flavonols occur widely in nature in plants, including tea, berries, and vegetables [40]. The flavonol concentration in red wine is about 30 times higher that of resveratrol, and the major flavonol components in red wine are 3,3',4',5,5',7-hexahydroxyflavone (myricetin, Figure 4) and 3,3',4',5,7pentahydroxyflavone (quercetin) [22], which typically represent $20-50 \%$ of the total flavonol content [22]. Several studies have shown that myricetin exhibited anticarcinogenic activities. It was indicated that myricetin had a potent antioxidant capacity [41] and suppressed cancer development induced by polycyclic aromatic hydrocarbons in SENCAR mice [42]. It has also been demonstrated that myricetin exerted protective effects against two-stage skin tumorigenesis [43] and inhibited the growth of A549 lung cancer cells [44]. In colorectal cancer cells, myricetin inhibited the activity of matrix metalloproteinase-2 [45].

Figure 4. Chemical structure of myricetin.<smiles>O=c1c(O)c(-c2cc(O)c(O)c(O)c2)oc2cc(O)cc(O)c12</smiles> 
Recently, Lee and coworkers reported that myricetin inhibited 12-O-tetradecanoylphorbol-13acetate (phorbol ester)-induced COX-2 expression in JB6 P+ mouse epidermal (JB6 P+) cells by suppressing activation of nuclear factor kappa B (NF- $\mathrm{B}$ ). Myricetin inhibited phorbol ester-induced upregulation of COX-2 protein, while resveratrol at the same concentration did not exert significant effects. The phorbol ester-induced production of prostaglandin E2 was also attenuated by myricetin treatment. Myricetin inhibited both COX-2 and NF- $\mathrm{KB}$ transactivation in phorbol ester-treated JB6 P+ cells. Myricetin blocked the phorbol ester-stimulated DNA binding activity of NF- $\kappa \mathrm{B}$. In addition, red wine extract inhibited phorbol ester-induced COX-2 expression and NF- $\mathrm{BB}$ transactivation in JB6 P+ cells. These results revealed that myricetin contributes to the chemopreventive effects of red wine through inhibition of COX-2 expression by blocking the activation of NF- $\kappa \mathrm{B}$ [46].

Lee and coworkers subsequently reported that myricetin was a novel inhibitor of mitogen-activated protein kinase kinase (MEK)1 activity and transformation of JB6 P+ mouse epidermal cells [47]. Myricetin $(10 \mu \mathrm{M})$ inhibited 12-O-tetradecanoylphorbol-13-acetate (TPA) or epidermal growth factor (EGF)-induced cell transformation by 76 or $72 \%$, respectively, compared with respective reductions of 26 or $19 \%$ by resveratrol $(20 \mu \mathrm{M})$. A combination of myricetin and resveratrol exerted additive but not synergistic effects on either TPA- or EGF- induced transformation. Myricetin, but not resveratrol, attenuated tumor promoter-induced activation of c-fos or activator protein-1. Myricetin strongly inhibited MEK1 kinase activity and suppressed TPA- or EGF- induced phosphorylation of extracellular signal-regulated kinase (ERK) or p90 ribosomal S6 kinase, downstream targets of MEK. Moreover, myricetin inhibited H-Ras-induced cell transformation more effectively than either PD098059, a MEK inhibitor, or resveratrol. Myricetin directly bound with glutathione $S$-transferaseMEK1 but did not compete with ATP. These results indicated that myricetin had potent anticancerpromoting activity and mainly targets MEK signaling, which may contribute to the chemopreventive potential of red wines.

\section{Conclusions}

Chemoprevention in combination with anticancer treatment represents an important approach to reduce morbidity and mortality from cancer. Red wines contain a large array of polyphenolic constituents that have been shown to block carcinogenesis and to inhibit the growth of tumors in whole animals, or in cell culture by altering the activity of certain enzymes or the expression of specific genes.

Red wine polyphenol extracts and fractions were reported to delay tumor onset in transgenic mice, inhibit azoxymethane (AOM) induced intestinal carcinogenesis by modulation of gene expression, inhibit epidermal growth factor induced the proliferation of transformed colon epithelial cells by modulation of activation of mitogen-activated protein kinases and show selective cytotoxicity against MCF-7 breast cancer cells. Supported by above exciting evidence, further investigation on cancer chemopreventive activities of red wine polyphenol extracts and fractions are strongly recommended.

Red wine polyphenols were found to be potent aromatase inhibitors, indicating potential treatment of breast cancer, since aromatase plays an important role in the carcinogenesis of breast cancer. The previous hypothesis that red wine had stronger anti-cancer activities than white wine was confirmed by the difference in inhibition of aromatase activity. An extensive study revealed that the procyanidin B 
dimers were identified to be the active principles. Further in vitro and in vivo studies demonstrated that procyanidin B dimers in red wine and grape seeds were potential chemopreventive agents against breast cancer by suppressing in situ estrogen biosynthesis.

Recent findings have demonstrated potent anticancer-promoting activity for myricetin, which mainly targeted MEK signaling and inhibited COX-2 expression by blocking the activation of NF- $\kappa \mathrm{B}$. Although resveratrol was believed to be a promising cancer chemopreventive agent from red wine, the search for other novel cancer chemopreventive polyphenols, like myricetin, is also of significance.

\section{Acknowledgements}

Financial support from the NSFC (20772109) and the NCET-06-520 is gratefully acknowledged.

\section{References}

1. Surh, Y.-J. Cancer chemoprevention with dietary phytochemicals. Nat. Rev. Cancer 2003, 3, 768780.

2. World Cancer Research Fund and American Institute for Cancer Research. Food Nutrition and the prevention of cancer: a global perspective; BANTA Press: Menasha, WI, USA, 1997.

3. Kato, R.; Nakadate, T.; Yamamoto, S.; Sugimura, T. Inhibition of 12-O-tetradecanoylphorbol- 13acetate-induced tumor promotion and ornithine decarboxylase activity by quercetin: possible involvement of lipoxygenase inhibition. Carcinogenesis 1983, 4, 1301-1305.

4. Lesca, P. Protective effects of ellagic acid and other plant phenols on benzo(a)pyrene-induced neoplasia in mice. Carcinogenesis 1983, 4, 1651-1653.

5. Muhktar, H; Das, M; Khan, W. A.; Wang, Z. Y.; Bik, D. P.; Bickers, D. R. Exceptional activity of tannic acid among naturally occurring plant phenols in protecting against 7, 12dimethylbenz(a)anthracene-, benzo(a)pyrene-, 3-methylcholanthrene-, and N-methyl-N-nitrosourea-induced skin tumorigenesis in mice. Cancer Res. 1988, 48, 2361-2365.

6. Huang, M. T.; Ferraro, T. Phenolic compounds in food and cancer prevention. In Phenolic compounds in food and their effects on health; Huang, H. T., Ho, C. T., Lee, C. Y., Eds.; American Chemical Society: Washington, DC, USA, 1992; pp. 8-34.

7. Gali, H. U.; Perchellet, E. M.; Klish, D. S.; Johnson, J. M.; Perchellet, J. P. Antitumor-promoting activities of hydrolyzable tannins in mouse skin. Carcinogenesis 1992, 13, 715-718.

8. Gali, H. U.; Perchellet, E. M.; Klish, D. S.; Johnson, J. M.; Perchellet, J. P. Hydrolyzable tannins: potent inhibitors of hydroperoxide production and tumor promotion in mouse skin treated with 2-0tetradecanoylphorbol-13-acetate in vivo. Int. J. Cancer 1992, 51, 425-432.

9. Yin, P.; Zhao, J.; Cheng, S.; Hara, Y.; Zhu. Q.; Liu Z. Experimental studies of the inhibitory effects of green tea catechin on mice large intestinal cancers induced by 1,2-dimethylhydrazine. Cancer Lett. 1994, 79, 33-38.

10. Menon, L. O.; Kuttan, R.; Kuttan, O. Inhibition of lung metastasis in mice induced by B16F1O melanoma cells by polyphenolic compounds. Cancer Lett. 1995, 95, 221-225.

11. Soleas, G. J.; Diamandis, E. P.; Goldberg, D. M. Wine as a biological fluid: History, production, and role in disease prevention. J. Clin. Lab. Anal. 1997, 11, 287-313. 
12. Bradlow, H. L.; Telang, N. T.; Sepkovic, D. W.; Osborne, M. P. Phytochemicals as modulators of cancer risk. Adv. Exp. Med. Biol. 1999, 472, 207-221.

13. Yang, C. S.; Landau, J. M.; Huang, M. T.; Newmark, H. L. Inhibition of carcinogenesis by dietary polyphenolic compounds. Annu. Rev. Nutr. 2001, 21, 381-406.

14. Soleas, G. J.; Diamandis, E. P.; Goldberg, D. M. The world of resveratrol. In Nutrition and cancer prevention: new insights into the role of phytochemicals; American Institute for Cancer Research, Ed.; Kluwer Academic Publishers/Plenum Publishers: New York, NY, 2001.

15. Pedersen, A.; Johansen, C.; Gronbaek, M. Relations between amount and type of alcohol and colon and rectal cancer in a Danish population based cohort study. Gut 2003, 52, 861-867.

16. Jang, M.; Cai, L.; Udeani, G. O.;Slowing, K. V.; Thomas, C. F.; Beecher, C. W. W.; Kinghorn, D.; Mehta, R. G.; Moon, R. C.; Pezzuto, J. M. Cancer chemopreventive activity of resveratrol, a natural product derived from grapes. Science 1997, 275, 218-220.

17. Kundu, J. K.; Surh, Y.-J. Molecular basis of chemoprevention by resveratrol: NF- $\mathrm{BB}$ and AP-1 as potential targets. Mutat. Res. 2004, 555, 65-80 and references cited therein.

18. Shankar, S.; Singh, G.; Srivastava, R. K. Chemoprevention by resveratrol: molecular mechanisms and therapeutic potential. Front. Biosci. 2007, 12, 4839-4854 and references cited therein.

19. EIAttar, T. M.; Virji, A. S. Modulating effect of resveratrol and quercetin on oral cancer cell growth and proliferation. Anti-Cancer drugs 1999, 10, 187-193.

20. Soleas, G. J.; Goldberg, D. M.; Grass, L.; Levesque, M.; Diamandis, E. P. Do wine polyphenols modulate p53 gene expression in human cancer cell lines? Clin. Biochem. 2001, 34, 415-420.

21. Soleas, G. J.; Grass, L.; Josephy, P. D.; Goldberg, D. M.; Diamandis, E. P. A comparison of the anticarcinogenic properties of four red wine polyphenols. Clin. Biochem. 2002, 35, 119-124.

22. Waterhouse, A. L. Wine phenolics. Ann. N. Y. Acad. Sci. 2002, 957, 21-36.

23. Clifford, A. J.; Ebeler, S. E.; Ebeler, J. D.; Bills, N. D.; Hinrichs, S. H.; Teissedre, P.-L.; Waterhouse, A. L. Delayed tumor onset in transgenic mice fed an amino acidbased diet supplemented with red wine solids. Am. J. Clin. Nutr. 1996, 64, 748-756.

24. Caderni, G.; De Filippo, C.; Luceri, C.; Salvadori, M.; Giannini, A.; Biggeri, A.; Remy, S.; Cheynier, V.; Dolara, P. Effects of black tea, green tea and wine extracts on intestinal carcinogenesis induced by azoxymethane in F344 rats. Carcinogenesis, 2000, 21, 1965-1969.

25. Caderni, G.; Remy, S.; Cheynier, V.; Morozzi, G.; Dolara, P. Effect of complex polyphenols on colon carcinogenesis. Eur. J. Nutr. 1999, 38, 126-132.

26. Femia, A. P.; Caderni, G.; Vignali, F.; Salvadori, M.; Giannini, A.; Biggeri, A.; Gee, J.; Przybylska, K.; Cheynier, V.; Dolara, P. Effect of polyphenolic extracts from red wine and 4-OHcoumaric acid on 1,2-dimethylhydrazine-induced colon carcinogenesis in rats. Eur. J. Nutr. 2005, 44, $79-84$.

27. Briviba, K.; Pan, L.; Rechkemmer, G. Red wine polyphenols inhibit the growth of colon carcinoma cells and modulate the activation pattern of mitogen-activated protein kinases. J. Nutr. 2002, 132, 2814-2818.

28. Dolara, P.; Luceri, C.; De Filippo, C.; Femia, A. P.; Giovannelli, L.; Caderni, G.; Cecchini, C.; Silvi, S.; Orpianesi, C.; Cresci, A. Red wine polyphenols influence carcinogenesis, intestinal microflora, oxidative damage and gene expression profiles of colonic mucosa in F344 rats. Mutat. Res. 2005, 591, 237-246. 
29. Hakimuddin, F.; Paliyath, G.; Meckling, K. Treatment of mcf-7 breast cancer cells with a red grape wine polyphenol fraction results in disruption of calcium homeostasis and cell cycle arrest causing selective cytotoxicity. J. Agric. Food Chem. 2006, 54, 7912-7923.

30. Esteban, J.; Warsi, Z.; Haniu, M.; Hall, P.; Shively, J. E.; Chen, S. Detection of intratumoral aromatase in breast carcinomas: an immunohistochemical study with clinicopathologic correlation. Am. J. Pathol. 1992, 140, 337-343.

31. Bulun, S. E.; Price, T. M.; Mahendroo, M. S.; Aitken, J.; Simpson, E. R. A link between breast cancer and local estrogen biosynthesis suggested by quantification of breast adipose tissue aromatase cytochrome P450 transcripts using competitive polymerase chain reaction after reverse transcription. J. Clin. Endocrinol. Metab. 1993, 77, 1622-1628.

32. Santen, R. J.; Martel, H.; Hoagland, M.; Naftolin, F.; Roa, L.; Harada, N.; Hafer, L.; Zaino, R.; Santner, S. J. Stromal spindle cells contain aromatase in human breast tumors. J. Clin. Endocrinol. Metab. 1994, 79, 627-632.

33. Lu, Q.; Nakmura, J.; Savinov, A.; Yue, W.; Weisz, J.; Dabbs, D. J.; Wolz, G.; Brodie, A. Expression of aromatase protein and messenger ribonucleic acid in tumor epithelial cells and evidence of functional significance of locally produced estrogen in human breast cancers. Endocrinology 1996, 137, 3061-3068.

34. Tekmal, R. R.; Ramachandra, N.; Gubba, S.; Durgam, V. R.; Mantione, J.; Toda, K.; Shizuta, Y.; Dillehay, D. L. Overexpression on int-5/aromatase in mammary glands of transgenic mice results in the induction of hyperplasia and nuclear abnormalities. Cancer Res. 1996, 56, 3180-3185.

35. Yue, W.; Wang, J. P.; Hamilton, C. J.; Demers, L. M.; Santen, R. J. In situ aromatization enhances breast tumor estradiol levels and cellular proliferation. Cancer Res. 1998, 58, 927-932.

36. Chen, S.; Sun, X. Z.; Kao, Y. C.; Kwon, A.; Zhou, D.; Eng, E. Suppression of breast cancer cell growth with grape juice. Pharm. Biol. 1998, 36, 53-61.

37. Eng, E. T.; Williams, D.; Mandava, U.; Kirma, N.; Tekmal, R. R.; Chen, S. Suppression of aromatase (estrogen synthetase) by red wine phytochemicals, Breast Cancer Res. Treat. 2001, 67, 133-146.

38. Eng, E. T.; Williams, D.; Mandava, U.; Kirma, N.; Tekmal, R. R.; Chen, S. Anti-aromatase chemicals in red wine. Ann. N. Y. Acad. Sci. 2002, 963, 239-246.

39. Eng, E. T.; Ye, J. J.; Williams, D.; Phung, S.; Moore, R. E.; Young, M. K.; Ugis, G.; Braunstein, G.; Chen, S. Suppression of estrogen biosynthesis by procyanidin dimers in red wine and grape seeds. Cancer Res. 2003, 63, 8516-8522.

40. Hertog, M. G.; Feskens, E. J.; Hollman, P. C.; Katan, M. B.; Kromhout, D. Dietary antioxidant flavonoids and risk of coronary heart disease: the Zutphen Elderly Study. Lancet 1993, 342, 1007 1011.

41. Noroozi, M.; Angerson, W. J.; Lean, M. E. Effects of flavonoids and vitamin C on oxidative DNA damage to human lymphocytes. Am. J. Clin. Nutr. 1998, 67, 1210-1218.

42. Mukhtar, H.; Das, M.; Khan, W. A.; Wang, Z. Y.; Bik, D. P.; Bickers, D. R. Exceptional activity of tannic acid among naturally occurring plant phenols in protecting against 7,12dimethylbenz(a)anthracene-, benzo(a)pyrene-, 3-methylcholanthrene-, and Nmethyl-N-nitrosoureainduced skin tumorigenesis in mice. Cancer Res. 1988, 48, 2361-2365. 
43. Chang, R. L.; Huang, M. T.; Wood, A. W.; Wong, C. Q.; Newmark, H. L.; Yagi, H.; Sayer, J. M.; Jerina, D. M.; Conney, A. H. Effect of ellagic acid and hydroxylated flavonoids on the tumorigenicity of benzo[a]pyrene and (+/-)-7 beta, 8 alphadihydroxy- 9 alpha, 10 alpha-epoxy7,8,9,10-tetrahydrobenzo[a]pyrene on mouse skin and in the newborn mouse. Carcinogenesis 1985, 6, 1127-1133.

44. Das, M.; Khan, W. A.; Asokan, P.; Bickers, D. R.; Mukhtar, H. Inhibition of polycyclic aromatic hydrocarbon-DNA adduct formation in epidermis and lungs of SENCAR mice by naturally occurring plant phenols. Cancer Res. 1987, 47, 767-773.

45. Ko, C. H.; Shen, S. C.; Lee, T. J.; Chen, Y. C. Myricetin inhibits matrix metalloproteinase 2 protein expression and enzyme activity in colorectal carcinoma cells. Mol. Cancer Ther. 2005, 4, 281-290.

46. Lee, K. M.; Kang, N. J.; Han, J. H.; Lee, K. W.; Lee, H. J. Myricetin down-regulates phorbol esterinduced cyclooxygenase- 2 expression in mouse epidermal cells by blocking activation of nuclear factor kappa B. J. Agric. Food Chem. 2007, 55, 9678-9684.

47. Lee, K. W.; Kang, N. J.; Rogozin, E. A.; Kim, H.-G.; Cho, Y. Y.; Bode, A. M.; Lee, H. J.; Surh, Y.-J.; Bowden, G. T.; Dong, Z. Myricetin is a novel natural inhibitor of neoplastic cell transformation and MEK1. Carcinogenesis 2007, 28, 1918-1927.

(C) 2008 by the authors; licensee Molecular Diversity Preservation International, Basel, Switzerland. This article is an open-access article distributed under the terms and conditions of the Creative Commons Attribution license (http://creativecommons.org/licenses/by/3.0/). 